\title{
O Ensino Fundamental de nove anos e os processos de avaliação: estratégias de regulação da população infantil
}

Maria Renata Alonso Mota*

\section{Resumo}

Este artigo é parte da tese de doutorado que teve como objetivo discutir como o Ensino Fundamental de nove anos está inserido em práticas de governamento da infância e, ainda, como essas práticas possibilitam outro lugar escolar para as crianças de seis anos. O estudo busca compreender o que pode ser dito e pensado sobre os espaços e lugares que estão sendo destinados às crianças menores de sete anos e como isso vem produzindo o governamento da infância, a partir da noção de governamentalidade desenvolvida por Michel Foucault. Como material de pesquisa, foram utilizados alguns documentos que tratam da política de Ensino Fundamental de nove anos elaborados pelo Ministério da Educação e pela Secretaria de Educação do Estado do Rio Grande do Sul, bem como matérias jornalísticas que foram publicadas sobre o assunto no período mais intenso da implementação do Ensino Fundamental de nove anos (2005-2008). Neste artigo, as análises estão centradas nos processos de avaliação implicados nesta política educacional como uma das estratégias eficazes de regulação da população. Os resultados apontam para o fato de que as políticas educacionais contemporâneas, como é o caso do Ensino Fundamental de nove anos, ainda que enfoquem o direito à educação e a universalização da educação escolar para as crianças de seis anos e que pretendam incidir no sucesso escolar por meio das estratégias que utilizam, propõem novos modelos institucionais, novos modelos de aprendizagem, novos modelos de infância e criança.

Palavras-chave: Ensino Fundamental de nove anos, infância, governamento, governamentalidade.

\section{Nine-year Elementary Education and the evaluation processes: strategies to govern the children population}

\section{Abstract}

This paper is part of a doctorate thesis that aimed at discussing how the nineyear Elementary Education has been inserted in childhood governing practices and how these practices provide six-year-old children with another school place. The study seeks to understand what can be said and thought about spaces and places designed for children under seven years old and how this has produced childhood government, considering the notion of governmentality developed by

\footnotetext{
* Professora Doutora do Instituto de Educação da Universidade Federal do Rio Grande (FURG). Rio Grande, Rio Grande do Sul, Brasil.
} 


\section{Maria Renata Alonso Mota}

Michel Foucault. The research material is composed of some documents related to the nine-year Elementary Education policy designed by the Ministry of Education and the Secretary of Education of the State of Rio Grande do Sul. The material also includes some reports that were published along the period in which the implementation of the nine-year Elementary Education was more intense (2005-2008). In this paper, the analysis has focused on the evaluation processes involved in that educational policy as one of the effective strategies to regulate the population. The results have pointed out the fact that contemporary educational policies, as it is the case of the nine-year Elementary Education, despite focusing on both the right to education and the universalization of school education for six-year-old children, and intending to act on school success through the strategies they use, propose new institutional models, new learning models, and new childhood and children models.

Keywords: Nine-year Elementary Education, childhood, government, governmentality.

No Brasil, atualmente, estamos vivendo um reordenamento com relação ao Ensino Fundamental, o que tem gerado ações governamentais no sentido de efetivar a ampliação do Ensino Fundamental para nove anos de duração, com início aos seis anos de idade. Essa efetivação se faz necessária em razão da aprovação da Lei oㅜ 11.274, de 6 de fevereiro de 2006, que alterou a redação dos artigos 29, 30, 32 e 87 da Lei de Diretrizes e Bases da Educação Nacional (Lei no 9394/96), ampliando para nove anos a duração do Ensino Fundamental.

Neste artigo apresento alguns dos achados da pesquisa que realizei em nível de doutorado, ${ }^{1}$ que teve como objetivo discutir como o Ensino Fundamental de nove anos está inserido em práticas de governamento da infânciae, ainda, como essas práticas possibilitam um outro lugar escolar para as crianças de seis anos. Tal objetivo pareceu-me importante, uma vez que a implantação do Ensino Fundamental de nove anos poderia mudar as relações entre as crianças e a escola, podendo mudar também os modos de ser criança.

O estudo que propus está interessado em analisar a vontade de verdade dos discursos oficiais produzidos na política de Ensino Fundamental de nove anos no que diz respeito ao lugar produzido para as crianças de seis anos. Minha pretensão, então, é compreender o que pode ser dito e pensado sobre os espaços e lugares destinados às crianças menores de sete anos e como isso produz o governamento ${ }^{2}$ da infância. Para tal, faço algumas aproximações com o pensamento de Michel Foucault, entre outros autores que assumem uma perspectiva pós-estruturalista.

Para empreender esta análise, busquei alguns materiais que pudessem dar suporte ao que pretendia. Esses materiais, ao comporem o corpus de 
O Ensino Fundamental de nove anos e os processos de avaliação: estratégias de regulação da população infantil

análise, não foram percebidos, conforme aponta Fischer (2007), como realidades mudas que, a partir da análise, revelariam sentidos escondidos; eles foram olhados como um conjunto de textos que estão associados a práticas sociais. Foram analisados, então, como práticas que são, que constituem sujeitos e corpos, bem como modos de existência de pessoas e instituições. Os textos foram vistos "na sua materialidade pura e simples de coisas ditas em determinado tempo e lugar" (FISCHER, 2007, p. 43-44).

Utilizei como material de pesquisa alguns documentos que tratam da política de Ensino Fundamental de nove anos elaborados pelo Ministério da Educação e pela Secretaria de Educação do Estado do Rio Grande do Sul, bem como matérias jornalísticas que foram publicadas sobre o assunto no período mais intenso da implementação do Ensino Fundamental de nove anos (2005 2008). Minha opção por esses materiais justifica-se em razão de que eles constituem discursos que são produzidos e legitimados como verdadeiros com relação ao Ensino Fundamental de nove anos.

Cabe destacar, ainda, que os conceitos de governamento e governamentalidade foram ferramentas centrais para o desenvolvimento das análises empreendidas. O que Foucault chama de governamentalidade é o conjunto de tecnologias que possibilitam exercer uma forma específica de poder cujo centro será a população. A governamentalidade é "o resultado do processo pelo qual o Estado de justiça da Idade Média, que nos séculos XV e XVI se tornou o Estado administrativo, viu-se pouco a pouco 'governamentalizado'" (FOUCAULT, 2008b, p. 144). Dizendo de outra forma, o que Foucault tenta assinalar é que o importante, para a nossa atualidade, não é tanto a estatização da sociedade, mas a governamentalização do Estado, afirmando que, desde o século XVIII, vivemos na era da governamentalidade:

Governamentalização do Estado, que é um fenômeno particularmente tortuoso, pois, embora efetivamente os problemas da governamentalidade, as técnicas de governo tenham se tornado de fato o único intuito político e o único espaço real da luta e dos embates políticos, essa governamentalização do Estado foi, apesar de tudo, o fenômeno que permitiu ao Estado sobreviver. [...] são as táticas de governo que, a cada instante, permitem definir o que deve ser do âmbito do Estado e o que não deve, o que é público e o que é privado, o que é estatal e o que é não-estatal. Portanto, se quiserem, o Estado em sua sobrevivência e o Estado em seus limites só devem ser compreendidos a partir das táticas gerais da governamentalidade. (FOUCAULT, 2008b, p. 145)

É nesse sentido que percebo a produtividade do conceito foucaultiano de governamentalidade. No âmbito deste estudo, tal ferramenta foi compreendida como uma grade pela qual tentei ver a disposição das coisas - neste caso 


\section{Maria Renata Alonso Mota}

específico, o Ensino Fundamental de nove anos, visto enquanto política voltada para a educação das crianças e implicada em um dispositivo de subjetivação que foi inventado. Operar com esse conceito possibilita percebermos os efeitos dessa política no governamento das crianças pequenas. Em razão disso, começo falando sobre a governamentalidade neoliberal, dada a relevância para este estudo.

\section{A razão governamental neoliberal}

Foucault, nos cursos ministrados no Collège de France - Segurança, Território, População, em 1978, e Nascimento da Biopolítica, em 1979-, apresenta uma série de análises que podem ser fortemente conectadas com a atualidade. Com a noção de governamentalidade, desenvolvida em ambos os cursos, aborda a questão do governo enquanto arte de governar implicada na conduta dos homens. No curso de 1979, Foucault discute não só as características dessa primeira forma de governamentalidade que se organiza entre os séculos XVI e XVII, mas também outras "artes de governar": o liberalismo do século XVIII e o neoliberalismo alemão e norte-americano do século XX.

Não pretendo fazer uma revisão de todos os aspectos analisados por Foucault nesses cursos. Meu intuito é tão somente destacar alguns dos aspectos por ele levantados no que diz respeito à razão governamental neoliberal na sua versão norte-americana, dada a centralidade que essa noção ocupa nas análises que empreendi.

A partir da aula de 14 de março de 1979 até a última aula do curso Nascimento da biopolítica, Foucault (2008a) aborda especificamente o neoliberalismo em sua vertente norte-americana. Para ele, o alvo do pensamento neoliberal norte-americano constitui-se de três elementos contextuais: a política keynesiana, os pactos sociais de guerra e o crescimento da administração federal por meio dos programas econômicos e sociais.

O neoliberalismo norte-americano é uma maneira de ser e pensar. É um tipo de relação entre governantes e governados, muito mais que uma técnica de governo, não se apresentando só nem totalmente como uma alternativa política; "se trata de uma reivindicação global, multiforme, ambígua, com ancoragem à direita e à esquerda. [...] É também um método de pensamento, uma grade de análise econômica e sociológica" (FOUCAULT, 2008a, p. 301). O neoliberalismo, a partir de tal perspectiva, precisa ser compreendido como um estilo geral de pensamento, e não como uma alternativa técnica de governo, muito menos como uma ideologia.

Para Foucault (2008a), o neoliberalismo americano aplica a grade econômica para decifrar problemas que não são propriamente econômicos para decifrar os fenômenos sociais. Essa generalização ilimitada da forma econômica do mercado em todo o corpo social funciona como princípio de inteligibilidade 
O Ensino Fundamental de nove anos e os processos de avaliação: estratégias de regulação da população infantil

que possibilita decifrar as relações sociais e os comportamentos individuais, como, por exemplo, as relações familiares e as relações educacionais.

Por outro lado, de acordo com Foucault (2008a), essa generalização da grade econômica vai permitir também testar a ação governamental. Trata-se, então, de possibilitar uma crítica à governamentalidade exercida em termos de mercado, com base em termos econômicos. Diferentemente do liberalismo clássico, em que o governo se "deixava-fazer" e o mercado era visto como um princípio de autolimitação, no neoliberalismo, o laissez-faire transforma-se em não deixar o governo fazer. O mercado converte-se em um tribunal econômico permanente frente ao governo. Diferentemente do século XIX, que procurou estabelecer "uma espécie de jurisdição administrativa que permitisse aferir a ação do poder público em termos de direito, temos aqui uma espécie de tribunal econômico que pretende aferir a ação do governo em termos estritamente de economia e de mercado" (FOUCAULT, 2008a, p. 339). Porém, como afirma Rose (1997), ainda que o neoliberalismo se apresente como uma crítica ao governo, não abandona a "vontade de governar", mantendo a visão de que o fracasso do governo pode ser superado com a invenção de novas estratégias.

De acordo com Rose (1997), o neoliberalismo adota novas estratégias de governamento, sendo algumas delas apresentadas pelo autor: uma nova relação entre expertise e política, uma nova pluralização das tecnologias sociais e uma nova especificação do sujeito de governo.

No que diz respeito à relação entre expertise e política, o autor destaca que no neoliberalismo ocorre uma transformação das atividades, que passam a ser monetarizadas, estabelecendo-se novas relações de poder. Assim, a mercantilização, por exemplo, abarca uma noção de "mercado livre", em que as relações entre cidadãos e experts não são organizadas por meio da obrigatoriedade, mas através de atos de escolha. A partir de novas relações mais distanciadas de controle entre os centros políticos de decisão e os dispositivos, como escolas, hospitais ou empresas, o risco passa a ser algo manejável. Sendo sobre essas instituições que recai, novamente, a responsabilidade acerca da saúde, da riqueza e da felicidade, elas são constantemente submetidas a exames aparentemente flexíveis, mas que se convertem em estratégias eficazes para o governamento a distância.

Com relação à segunda estratégia, Rose (1997) afirma que no neoliberalismo há uma tendência à desregulamentação do Estado, fenômeno que está associado à mudança que ocorre no conceito do que se considera como "o social". O social exigia a intervenção direta do Estado. Agora, com o neoliberalismo, o que passa a ser fundamental é a relação entre o indivíduo responsável e sua comunidade autogovernada. Com essa mudança com relação ao social, ocorre uma perda de centralidade nas tecnologias de regulação, abrindo espaço para a produção de poderes e vontades autônomas de empresas, organizações, profissionais, indivíduos, etc. Ocorre, então uma prolifera- 


\section{Maria Renata Alonso Mota}

ção de organizações não governamentais, que assumem uma série de funções reguladoras, de planejamento e de educação, havendo aí um deslocamento na concepção de poder político.

Por fim, o autor destaca a reconfiguração na definição dos sujeitos de governo que ocorre no neoliberalismo. Estes são considerados como indivíduos ativos que buscam sua própria realização, maximizando sua qualidade de vida mediante atos de escolha e conferindo às suas vidas um determinado sentido, na medida em que elas podem ser racionalizadas como o resultado de escolhas feitas ou de opções por tomar. A racionalidade neoliberal exige, então, um indivíduo livre e autônomo, o que supõe um eu ativamente responsável para cumprir suas obrigações, que não são de uns para com os outros, mas de realizações individuais. A questão passa a ser encontrar meios para que os indivíduos se sintam responsáveis mediante opções individuais que adotam para si mesmos.

Ao desenvolver o estudo, percebi que o modo como a política de Ensino Fundamental de nove anos vem sendo gerida nas escolas tem toda uma ênfase na gestão prioritariamente de resultados. Essa política educacional parece, então, estar centrada na lógica de um Estado avaliador.

\section{Os processos de avaliação como estratégia de regulação}

O discurso que circula nos mais diversos projetos educacionais contemporâneos parece centrar-se na necessidade de participação de todos para a sua efetivação. No caso da política de Ensino Fundamental de nove anos, tal ênfase também parece evidente. Para que se alcance a universalização da educação escolar para as crianças de seis anos, para que se melhorem os índices de alfabetização, para que se combata a reprovação e a exclusão, parece ser necessária uma ampliação em termos de anos escolares, com início aos seis anos de idade. Porém, na direção desse discurso, não só o envolvimento das mais diversas esferas da sociedade é necessário para que o projeto alcance êxito e, assim, o Brasil cumpra com os compromissos assumidos diante da realidade da Educação Básica, atingindo melhores patamares em relação a outros países em desenvolvimento. Ao mesmo tempo, ampliam-se os meios e os apoios disponibilizados para que se efetivem os objetivos postos para tal projeto. Amplia-se o número de profissionais recrutados para colocar em prática tal intento. É o que percebo no projeto piloto para alfabetização das crianças de seis anos proposto pela Secretaria de Educação do Estado do Rio Grande do Sul em 2007.

A Secretaria de Estado da Educação do Rio Grande do Sul (SEDUC/RS), como coordenadora de políticas no âmbito do Estado, e a União Nacional de Dirigentes Municipais de Educação - Seção Rio Grande do Sul - Undime/RS, em regime de colaboração, com apoio do Escritório Antena da Unesco no Estado, propõem-se a implementar o presente projeto de alfabetização no Ensino Fundamental. [...] 
O Ensino Fundamental de nove anos e os processos de avaliação: estratégias de regulação da população infantil

Com esse objetivo, foram convidadas a participar dessa experiência quatro instituições com reconhecimento em âmbito nacional e comprovada competência na área da educação, especialmente da alfabetização e da avaliação educacional, a saber:

1) Grupo de Estudos sobre Educação, Metodologia de Pesquisa e Ação - Geempa, com sede em Porto Alegre/ $\mathrm{RS}$, que desenvolve programa de alfabetização com bases teóricas do pós-construtivismo (psicogênese da alfabetização - níveis pré-silábico, silábico e alfabético - e interação social nas aprendizagens).

2) Instituto Ayrton Senna, com sede em São Paulo/SP, que desenvolve programa de gerenciamento da aprendizagem nos primeiros anos do Ensino Fundamental, denominado Circuito Campeão, que promove ações para fortalecer a gestão do ensino e da aprendizagem, assegurando $95 \%$ de alfabetização no primeiro ano, mediante sistemática de acompanhamento e análise de resultados para a tomada de decisões.

3) Instituto Alfa e Beto, com sede em Belo Horizonte/MG, que desenvolve o programa Alfa e Beto para alfabetização de crianças de 6 e 7 anos, com base em método fônico que estabelece relações explícitas entre os fonemas e grafemas e utiliza materiais estruturados e com forte controle morfossintático.

4) Fundação Cesgranrio, com sede no Rio de Janeiro/RJ, instituição com comprovada experiência nacional em avaliação educacional que será responsável pela ava-liação dos resultados de aprendizagem dos alunos, por meio da aplicação, no início das aulas, de teste de prontidão para a alfabetização e, ao final do ano letivo, de teste composto por questões selecionadas com os respectivos responsáveis pelos três programas de alfabetização participantes da experiência. (SEDUC/RS, 2007, p. 07)

Estabeleço, aqui, relação com o estudo realizado por Traversini (2003), que analisa como o Programa Alfabetização Solidária (PAS) constitui-se numa forma de governamentalização da sociedade brasileira e dos indivíduos. Dentre os pontos de conexão com o estudo realizado pela autora, destaco dois aspectos que podem auxiliar na compreensão do que desenvolvo nesta seção.

O primeiro aspecto diz respeito ao envolvimento de outras instituições e profissionais no desenvolvimento e execução de projetos educacionais. Traversini (2003, p.152) chama a atenção para o fato de que a multiplicação dos empresários parceiros no Programa Alfabetização Solidária talvez não se dê apenas devido à responsabilidade social, mas também "porque apostar na educação é considerado um meio para a melhoria da economia e prosperidade nacional, o que beneficiaria suas empresas e a eles/as próprios/as". Na sua compreensão, a importância dada à alfabetização e à educação para o progres- 


\section{Maria Renata Alonso Mota}

so do país pode ser ainda maior se os programas educacionais pautarem sua atuação dando ênfase às competências, às avaliações padronizadas e às premiações. Ainda que a referência que a autora faz, diferentemente do estudo que realizo, enfoque a parceria solidária de empresários, penso que o mesmo se aplica a outras políticas educacionais. A política de Ensino Fundamental de nove anos e, de forma específica, a participação de instituições terceirizadas no projeto piloto de alfabetização proposto pela SE/RS, também pode ser compreendida como uma forma de melhoria da economia e da prosperidade nacional. Assim como Traversini (2003, p. 153), entendo que as políticas educacionais contemporâneas que possuem essas características "pode[m] ser considerada[s] como uma forma adequada de preparar os indivíduos para ingressarem em um mundo orientado para o mercado competitivo".

O outro aspecto, que está relacionado com o primeiro, diz respeito à expertise. Traversini (2003), ao analisar o Programa Alfabetização Solidária, enfatiza que os coordenadores universitários, os consultores, os empresários e os auditores são reconhecidos como autoridades. A autora chama a atenção para o fato de que, no mundo contemporâneo, também ocorre uma reconfiguração com relação ao papel dos experts. Com a emergência das sociedades neoliberais, há uma pluralização dos experts, "à medida que proliferam sujeitos de governamento, assim como a variedade de seus saberes passou a conformar uma complexa rede de informações por meio da qual as decisões são tomadas com base em custos e benefícios que determinado programa pode alcançar" (TRAVERSINI, 2003, p. 182-183).

Isso pode ser observado também no projeto piloto de alfabetização de crianças de seis anos no Rio Grande do Sul. Em tal projeto, o Geempa, o Instituto Ayrton Senna, o Instituto Alfa e Beto e a Cesgranrio são considerados, conforme explícito no próprio projeto, instituições de "comprovada eficácia". Não só os coordenadores das escolas e os secretários municipais e estaduais de educação estão autorizados a falar. Nesse caso, são convocadas instituições que têm experiência em gestão dos processos de alfabetização, bem como uma instituição com experiência em avaliação educacional, para compor os saberes que dão condições para que o projeto seja viabilizado.

Ao mesmo tempo em que tais instituições foram convocadas a ser parceiras de um projeto de alfabetização no Estado do Rio Grande do Sul, as escolas foram convidadas a participar de tal empreendimento e também a escoIher a instituição que serviria de apoio no processo de alfabetização das crianças de seis anos que estavam ingressando no primeiro ano do Ensino Fundamental de nove anos. No mesmo projeto citado anteriormente, a noção de autonomia na gestão é explicitada.

Para a seleção das turmas, serão mobilizados secretários municipais de educação, interessados em participar dessa iniciativa, e representantes dos órgãos regionais da Secretaria de Estado da Educação, que deverão 
O Ensino Fundamental de nove anos e os processos de avaliação: estratégias de regulação da população infantil

reunir os gestores escolares e professores alfabetizadores das escolas das duas redes de ensino, em cada município, para adesão ao projeto e escolha do programa de alfabetização a ser desenvolvido. São condições de participação: a adesão das escolas e dos alfabetizadores e a escolha de uma proposta para toda a rede pública, em cada município. (SEDUC/RS, 2007, p. 08)

Em matéria veiculada pelo jornal Zero Hora que aborda os três métodos empregados na alfabetização das crianças de seis anos adotados no projeto desenvolvido no Rio Grande do Sul desde 2007, a noção de autonomia também fica explícita.

Diretora adjunta do Departamento Pedagógico da SEC, Sônia Bier afirma que a ideia do governo não é escolher um modelo a ser seguido por todos os professores, mas definir que competências as crianças devem adquirir ao final da $1^{\text {a }}$ e da $2^{\underline{a}}$ séries com base nessa experiência. A SEC estuda, porém, ampliar o projeto piloto para um maior número de colégios no ano que vem. (ZERO HORA, 07/9/2008, p. 34)

Como podemos perceber nos excertos apresentados, aspectos como participação de todos os segmentos, autonomia e autogestão parecem ser primordiais para o alcance de determinados resultados. Com tais aspectos, que operam de forma contundente nas políticas educacionais contemporâneas, fica mais evidente o deslocamento que se opera da administração para uma ênfase na gestão - gestão que, nesse caso, precisa ser de resultados.

No caso específico da experiência implementada no Estado do Rio Grande do Sul, não há uma fórmula determinada, não há um método a ser seguido por todas as escolas. O método pode e deve ser escolhido pelos professores, escolas e secretarias municipais e estaduais. É a escolha individual que impera. A partir de um investimento privado e de uma noção de autogestão, busca-se, de forma descentralizada, alcançar os resultados esperados. Com tal perspectiva, cada um, cada instituição especializada, cada escola envolvida é responsável pelo sucesso ou fracasso da alfabetização. Além disso, cada escola parece ser percebida como uma consumidora de produtos educacionais, transformando a própria educação em mercadoria. "Por um lado, há a mudança do sujeito dependente para o consumidor/cidadão ativo. Por outro lado, há a mudança da burocracia impessoal para a gerência inovativa e empresarial" (BALL, 1998 , p. 130). As práticas democráticas parecem estender-se a todos e, ao mesmo tempo, estão relacionadas ao consumismo. Essa parece ser uma forma de colocar em funcionamento toda uma tecnologia de governamento, tanto no nível individual quanto no nível institucional. 


\section{Maria Renata Alonso Mota}

A autonomia e a liberdade são apenas aparentes, uma vez que elas são sempre reguladas. As escolas não são tão livres quanto parecem ser, já que as formas de controle externo são bastante intensas e eficazes. As escolas escolhem os métodos, as formas de gerir os processos de alfabetização, mas o Estado, que descentraliza os meios de ação, encontra estratégias bastante eficazes de regulação. Ball (1998, p. 123), ao falar das mudanças na forma e no alcance das atividades do Estado, afirma que "a terceirização, a desregulamentação e a privatização têm reduzido, tanto em termos práticos quanto em termos ideológicos, a capacidade de intervenção estatal direta. Entretanto, isso não significa dizer que esses dispositivos de política não fornecem novas formas de controle estatal e regulação".

Dentre essas novas formas de controle, cito as avaliações externas. Em âmbito nacional, faço referência à Provinha Brasil, criada pelo Ministério da Educação, através do Instituto Nacional de Estudos e Pesquisas Educacionais Anísio Teixeira (Inep), com o objetivo de diagnosticar o nível de alfabetização dos alunos no início do Ensino Fundamental, de modo a prevenir o diagnóstico tardio dos déficits de letramento. Na página do MEC, há um ícone exclusivamente direcionado a questões de esclarecimento e orientações sobre a Provinha Brasil. ${ }^{3}$ Dentre os diversos aspectos abordados, destaco dois que me parecem bastante relevantes. O primeiro diz respeito à aplicação do teste.

Quem aplica: Dependendo do foco que o gestor atribua à avaliação, o teste poderá ser aplicado:

- pelo próprio professor da turma, com o objetivo de monitorar e avaliar a aprendizagem de cada aluno ou turma;

- por outras pessoas indicadas e preparadas pela secretaria de educação, com a proposta de obter uma visão geral de cada unidade escolar, das diretorias ou de toda a rede de ensino sob a administração da secretaria. [...] Em qualquer um dos casos, para implementar a Provinha Brasil, é necessário que as secretarias de educação planejem as formas de aplicação e correção dos testes, assim como a interpretação, a utilização e a divulgação dos resultados, de acordo com os objetivos definidos para a avaliação.

Quem corrige? Os resultados poderão ser corrigidos pelo próprio professor da turma ou pelo aplicador do teste. Assim, o professor poderá saber o nível de desempenho de sua turma de modo imediato. Da mesma forma, os resultados de cada turma poderão ser coletados e agregados, a fim de ser ter um panorama da escola ou de toda a rede municipal ou estadual. 
O Ensino Fundamental de nove anos e os processos de avaliação: estratégias de regulação da população infantil

O segundo aspecto, explicitado nas perguntas e respostas mais frequentes, aborda os benefícios de participar do processo de avaliação proposto pelo MEC/INEP.

Os alunos poderão ter suas necessidades melhor atendidas mediante o diagnóstico realizado e, assim, espera-se que o seu processo de alfabetização aconteça satisfatoriamente.

Os professores alfabetizadores contarão com um instrumental valioso para identificar de forma sistemática as dificuldades de seus alunos, possibilitando a reorientação do que ensinar e de como ensinar. Além disso, as análises e interpretações dos resultados e os documentos pedagógicos a eles relacionados poderão constituir uma fonte de formação.

Os gestores poderão fazer escolhas bem fundamentadas em sua gestão. Terão à disposição elementos para o planejamento curricular e para subsidiar a formação continuada dos professores alfabetizadores, a fim de melhorar a qualidade do ensino em sua rede. (BRASIL, 2007)

Em âmbito estadual, no projeto piloto proposto pela Secretaria de Educação do Estado do Rio Grande do Sul, na parte III, intitulada Objetivo e metodologia, e na parte IV, cujo título é Estratégia de implementação, alguns parágrafos são dispensados para explicitar qual será o papel de cada uma dessas instituições, como será realizada a avaliação, quem será responsável por ela e em que momento ela será realizada.

Os programas de alfabetização que participarão desse projeto envolvem capacitação de professores e gestores, disponibilização de material didático adequado, acompanhamento e controle efetivos do processo ensinoaprendizagem, por meio de avaliações formativas aplicadas aos alunos em diferentes momentos do ano letivo. (SEDUC/RS, 2007, p. 8)

As escolas e gestores municipais escolhem o método a ser adotado no processo de alfabetização, e as instituições capacitam e acompanham os envolvidos no processo, sendo que uma delas terá o papel primordial de controlar os resultados por meio de avaliações. Tais avaliações, de acordo com o projeto elaborado pela SEDUC/RS, seriam realizadas em momentos diferentes.

Um dos aspectos que gostaria de enfatizar é o fato de que as políticas educacionais contemporâneas, como é o caso do Ensino Fundamental de nove anos, ainda que enfoquem o direito à educação e a universalização da educação escolar para as crianças de seis anos e que pretendam incidir no sucesso escolar por meio das estratégias que utilizam, propõem novos modelos 


\section{Maria Renata Alonso Mota}

institucionais, novos modelos de aprendizagem, novos modelos de infância e criança. O eixo dos projetos educacionais contemporâneos não está mais nos procedimentos adotados, mas nos resultados. O que está em jogo são os resultados que serão obtidos pelas escolas a partir de suas escolhas individuais. $O$ que está em jogo é a construção de um padrão mínimo de alfabetização para as crianças de seis anos que ingressaram no Ensino Fundamental de nove anos e é isso que possibilitará a regulação do processo. Os procedimentos adotados pelas escolas serão regulados por meio da supervisão e da avaliação externa.

Instaura-se aí uma cultura competitiva no campo da educação. Por meio de boletins de desempenho de cada aluno, de escalas de proficiências e de matrizes de competências e habilidades cognitivas, regulam-se os procedimentos, e cada escola passa a disputar melhores posições educacionais. Sobre essa questão, Peters (1999, p. 221) afirma que:

[...] os governos neoliberais têm argumentado em favor de um estado mínimo, proposta que tem se limitado à determinação dos direitos individuais construídos em termos de consumo, e em favor de uma exposição máxima de todos os fornecedores à competição ou à reivindicação, como uma forma de minimizar o poder de monopólio e maximizar a influência do consumidor sobre a qualidade e o tipo de serviços fornecidos. A aplicação desse raciocínio à educação é facilmente compreendida. Seus pressupostos teóricos nem sempre têm se tornado explícitos, mas eles partem claramente de uma perspectiva neoliberal, sancionando reformas na administração educacional no assim chamado movimento para devolver ou delegar a responsabilidade na medida em que isso for praticável, enquanto, ao mesmo tempo, se aumentam os poderes locais das escolas e pais, vistos como consumidores individuais de educação.

É assim que vão sendo colocadas em funcionamento algumas práticas empresariais no campo da educação. Os resultados obtidos por cada escola, a partir de um trabalho baseado na livre escolha, na autonomia e na autogestão, são constantemente confrontados com os obtidos por outras escolas. Por meio de tais estratégias, a eficiência, a competitividade e a concorrência vão sendo instauradas.

A partir dos aspectos analisados neste artigo sobre o Ensino Fundamental de nove anos com a inserção das crianças de seis anos, podemos depreender que a escola é foco de governamento. $O$ alvo são os sujeitos infantis, mas as práticas se dão por meio das instituições escolares. 
O Ensino Fundamental de nove anos e os processos de avaliação: estratégias de regulação da população infantil

\section{Referências}

BALL, S. J. Cidadania global, consumo e política educacional. In: SILVA, L. H. da (Org.). A escola cidadã no contexto da globalização. Petrópolis: Vozes, 1998. p. 121-137.

BRASIL. Lei n. 11.274, 6 de fevereiro de 2006. Altera a redação dos arts. 29 , 30, 32 e 87 da Lei n. 9.394/1996, que estabelece as diretrizes e bases da educação nacional, dispondo sobre a duração de 9 (nove) anos para o Ensino Fundamental, com matrícula obrigatória a partir dos 6 (seis) anos de idade.

BRASIL. Ministério da Educação. Secretaria de Educação Básica. Perguntas mais frequentes e respostas do departamento de políticas educacionais. Disponível em: http://portal.mec.gov.br/seb . Acesso em: 18 maio 2007.

ESTADO DO RIO GRANDE DO SUL. Projeto piloto para alfabetização de crianças com seis anos. Porto Alegre: Secretaria de Educação, 2007.

FISCHER, R. M. B. A paixão de trabalhar com Foucault. In: COSTA, M. V. (Org.). Caminhos investigativos I: novos olhares na pesquisa em educação. Rio de Janeiro: Lamparina Editora, 2007.

FOUCAULT, M. O sujeito e o poder. In: DREYFUS, Hubert; RABINOW, Paul. Michel Foucault, uma trajetória filosófica. Rio de Janeiro: Forense Universitária, 1995. p. 231-249.

Nascimento da biopolítica. Curso dado no Collège de France (19781979). São Paulo: Martins Fontes, 2008a.

Segurança, Território, População. Curso dado no Collège de France (1977-1978). São Paulo: Martins Fontes, 2008b.

PETERS, M. Governamentalidade neoliberal e educação. In: SILVA, T. T. da (Org.). O sujeito da educação: estudos foucaultianos. Petrópolis, Vozes, 1999. p. 211-224.

ROSE, N. El gobierno en las democracias liberales "avanzadas": del liberalismo al neoliberalismo. Archipiélago: cuadernos de crítica de la cultura, n. 29, 1997, p. $25-40$.

TRAVERSINI, C. Programa Alfabetização Solidária: o governamento de todos e de cada um. Tese de Doutorado. Programa de Pós-Graduação em Educação, Faculdade de Educação, UFRGS, Porto Alegre, 2003.

ZERO HORA.Três testes para a alfabetização. Porto Alegre, 07 de setembro de 2008, p. 34-35. 


\section{Maria Renata Alonso Mota}

\section{Notas}

1 Tese de Doutorado intitulada As crianças de seis anos no Ensino Fundamental de nove anos e o governamento da infância, defendida no Programa de Pós-Graduação em Educação da Universidade Federal do Rio Grande do Sul (UFRGS), em 2010, sob a orientação do prof. Dr. Alfredo Veiga Neto.

2 Utilizei governamento a partir da concepção de Foucault (1995, p. 243), como "um modo de ação que não age direta e imediatamente sobre os outros, mas que age sobre sua própria ação, sobre ações eventuais, ou atuais, futuras ou presentes".

3 Disponível em: http://portal.mec.gov.br. Acesso em: 10/04/2008.

\section{Correspondência}

Maria Renata Alonso Mota - Rua General Abreu, 70. Bairro Cidade Nova, CEP 96211-100, Rio Grande, Rio Grande do Sul.

E-mail: mariarenata@terra.com.br

Recebido em 25 de março de 2011

Aprovado em 22 de fevereiro de 2012 